\title{
Temporal associations among ovarian events in cattle during oestrous cycles with two and three follicular waves
}

\author{
O. J. Ginther, L. Knopf and J. P. Kastelic \\ University of Wisconsin-Madison, Department of Veterinary Science, 1655 Linden Drive, Madison, \\ WI 53706, USA
}

\begin{abstract}
Summary. For 18 two-wave interovulatory intervals in heifers, the follicular waves were first detected on Days $-0.2 \pm 0.1$ and $9.6 \pm 0.2$, and for 4 three-wave intervals on Days $-0.5 \pm 0.3,9.0 \pm 0.0$ and $16.0 \pm 1 \cdot 1$ (ovulation is Day 0 ). The day-to-day mean diameter profile of the dominant follicle of the 1 st wave and the day of emergence of the 2nd wave were not significantly different between 2-wave and 3-wave intervals. There were no indications, therefore, that events occurring during the first half of the interovulatory interval were associated with the later emergence of a 3 rd wave. The dominant ovulatory follicle differed significantly $(P<0.05$ at least) between 2 -wave and 3-wave intervals in day of emergence (Day 9.6 \pm 0.2 and 16.0 $\pm 1 \cdot 1$ ), length of interval from emergence of follicle to ovulation (10.9 \pm 0.4 and $6.8 \pm 0.6$ days), and diameter on day before ovulation (16.5 \pm 0.4 and $13.9 \pm 0.4 \mathrm{~mm})$. The mean length of 2-wave interovulatory intervals $(20.4 \pm 0.3$ days $)$ was shorter $(P<0.01)$ than for 3 -wave intervals (22.8 \pm 0.6 days). The mean day of luteal regression for 2 -wave and 3-wave intervals was $16.5 \pm 0.4$ and $19.2 \pm 0.5(P<0.01)$. For all intervals, luteal regression occurred after emergence of the ovulatory wave, and the next wave did not emerge until near the day of ovulation at the onset of the subsequent interovulatory interval. In conclusion, the emergence of a 3 rd wave was associated with a longer luteal phase, and the viable dominant follicle present at the time of luteolysis became the ovulatory follicle.
\end{abstract}

Keywords: follicles; corpus luteum; cattle; follicular waves

\section{Introduction}

A wave of follicular growth involves the synchronous development of a group of follicles. Rajakoski (1960) postulated that 2 waves of follicular activity occur during the bovine oestrous cycle on the basis of gross and histological examination of ovaries recovered on known days of the cycle. The two-wave hypothesis has been supported by the results of counting and measuring all ultrasonically detectable follicles and categorizing the follicles according to diameters; the resulting profiles of follicular numbers and diameters in various groupings were bimodal averaged over 14 (Pierson \& Ginther, 1986) and 58 (Pierson \& Ginther, 1987) interovulatory intervals. In studies involving daily ultrasonic monitoring of individual follicles, 6 of 8 (Pierson \& Ginther, 1988) and 9 of 10 (Knopf et al., 1989) interovulatory intervals had 2 waves of follicular activity and the remainder had 3 waves. In contrast, Ireland \& Roche (1987) postulated that the bovine oestrous cycle involves 3 waves of follicular activity based on the quantitation of oestrogens and other steroids in the follicles and ovarian veins at various times during the cycle. The results of ultrasonic monitoring of individual follicles (Savio et al., 1988; Sirois \& Fortune, 1988) have supported the 3-wave hypothesis; $81 \%$ and $80 \%$ of the oestrous cycles had more than 2 follicular waves in the two studies, respectively. The divergent results in various studies indicate that populations of heifers 
differ in the proportion of 2-wave and 3-wave interovulatory intervals. The factors responsible for 2 waves of follicular activity during some oestrous cycles versus 3 waves during others are not known.

The purpose of the present study was to compare follicular profiles for interovulatory intervals with 2 or 3 follicular waves and to study the temporal associations between follicular waves and between the follicular waves and the corpus luteum. It was anticipated that this approach would clarify the sequence of ovarian events associated with the emergence of a 3 rd follicular wave during some interovulatory intervals.

\section{Materials and Methods}

Fifteen sexually mature, nulliparous Hostein heifers, $1 \cdot 5-2 \cdot 5$ years of age, and weighing $380-500 \mathrm{~kg}$ were used during May to September. Ultrasound examinations were done once daily by a single operator under optimized conditions, as described by Pierson \& Ginther (1988). The ultrasound scanner was a real-time, B-mode instrument equipped with a $5 \mathrm{MHz}$, linear-array, intrarectal transducer. The 15 heifers were examined for $1-4$ interovulatory intervals for a total of 24 intervals: 10 of the interovulatory intervals were used previously to study the incidence of 2 versus 3 follicular waves (Knopf et al., 1989). The day of ovulation at the beginning of an interovulatory interval was designated Day 0. Sequential identification of individual follicles was done, as described by Knopf $e t$ al. (1989), for as many follicles as possible with antral diameters of $4 \mathrm{~mm}$ or more.

The dominant follicle of a wave was defined as the one that grew to at least $11 \mathrm{~mm}$ and exceeded the diameter of all other follicles in the wave. A subordinate follicle was defined as one that originated from the same follicular pool as a dominant follicle as indicated by: (1) its first detection within 2 days of the first detection of the dominant follicle and (2) an increase in diameter for at least 1 day after first detection. For the present study, only the largest subordinate follicle was considered. A wave of follicular activity was retrospectively identified by the presence of a dominant follicle whether or not subordinate follicles were individually identified in association with the emergence of the dominant follicle. The day of first detection of a 4 or $5 \mathrm{~mm}$ follicle that was retrospectively identified as a dominant follicle was taken as the first day of a wave. If the dominant follicle was not detected until it reached 6 or $7 \mathrm{~mm}$, the previous day was taken as the first day; this modification seemed justifiable on the basis of previous study (Knopf $e t$ $a l ., 1989)$ and was necessary in a minority $(27 \%)$ of the waves. The interovulatory intervals were classified into the following groups: (1) 2 follicular waves (1st wave with a dominant anovulatory follicle and 2 nd wave with a dominant ovulatory follicle), (2) 3 follicular waves (Ist and 2 nd waves with a dominant anovulatory follicle and 3 rd wave with a dominant ovulatory follicle), and (3) more than 3 follicular waves.

Each dominant anovulatory follicle and its largest subordinate was partitioned into growing, static and regressing phases. The growing phase extended from the lst day of a wave to the day that the follicle appeared to cease its progressive increase in diameter. The static phase extended from the last day of the growing phase to the lst day that the follicle appeared to begin a progressive decrease in diameter. The regressing phase extended from the last day of the static phase to the day the follicle was no longer detectable or identifiable or apparently ceased the progressive decrease in diameter. Partitioning into phases was done so that the day of cessation of growth and the day of initiation of regression could be related temporally to other ovarian events. To avoid bias, partitioning was done without knowledge of the other ovarian events. The ovulatory follicle was considered to be in a growing phase from first detection to ovulation, but its largest subordinate was partitioned.

The lengths of the interovulatory intervals and the days of emergence of waves were normalized for intervals with 2 waves and separately for intervals with 3 waves. The mean length of the interovulatory intervals was used as the normalized length of the intervals. Waves were classified as anovulatory and ovulatory for 2-wave intervals and Ist anovulatory, 2nd anovulatory and ovulatory, for 3-wave intervals. The mean day of emergence of the dominant follicle of each type of wave was used to assign each type of wave to a day on the normalized interovulatory-interval scale. The day of emergence was also used as a common starting point to characterize the day-to-day mean diameter profiles of the dominant follicles and the largest subordinates.

Differences between the dominant anovulatory follicle for 2-wave intervals and the 1st dominant anovulatory follicle for 3-wave intervals were examined by the Statistical Analysis System general linear models univariate analyses of variance for repeated measures with degrees of freedom modified by the Greenhouse-Geyser epsilon (SAS User's Guide, 1985). A significant main effect of wave or a wave-by-day interaction indicated that there were differences between the dominant follicles for 2-wave and 3-wave intervals. Similarly, the dominant anovulatory follicle of the 1st wave was compared to that of the 2 nd wave within the 3-wave intervals and the ovulatory follicle was compared between the 2-wave and 3-wave intervals. Also, the following end points for the dominant follicles were examined: maximum diameter attained, day of cessation of growth, and day of onset of regression. Comparisons between wavetypes were made by analyses of variance or paired $t$ tests. The corpus luteum was examined daily and an image of the largest cross-sectional area was frozen; diameters in two planes were taken for the entire gland and for any detected central cavities. The area of the cross-sectional images was estimated by 0.5 height $\times 0.5$ width $\times \pi$. The area of a cavity was subtracted from total area of the gland to estimate the area of luteal tissue. Mean luteal tissue areas were normalized to the interovulatory interval by using data for the first 9 days, i.e. Days 0 to 8 of the normalized interval, 
and in reverse direction from the end of the interovulatory interval to Day 9 of the normalized interval. The first day of a significant decrease in area after Day 9 was determined by paired $t$ tests. In addition, the day of onset of regression of the corpus luteum for individual intervals was defined as first day that met both of the following criteria: (1) luteal area less than for each of the previous 3 days and (2) the area continued to decrease thereafter. Defining the day of onset of luteal regression for individual intervals was done so that temporal associations could be made within intervals without the necessity of normalization. The following comparisons were made between 2-wave and 3-wave intervals by analyses of variance: (1) day of onset of luteal regression, (2) interval from onset of an ovulatory wave to luteal regression, (3) interval from luteal regression to ovulation, and (4) diameter of preovulatory follicle on day of luteal regression.

\section{Results}

Of the 24 interovulatory intervals, $20(83 \%)$ had 2 waves of follicular activity and the remainder had 3 waves. Two of the 2-wave intervals were not used because of incomplete data, yielding a total of 18 intervals. The mean ( \pm s.e.m.) length of the 2-wave interovulatory intervals (20.4 \pm 0.3 days) was shorter $(P<0.01)$ than that of the 3 -wave interval $(22.8 \pm 0.6$ days $)$. For normalization,

Table 1. Comparisons of follicular and luteal characteristics (mean \pm s.e.m.) between 2-wave and 3-wave interovulatory intervals

\begin{tabular}{|c|c|c|}
\hline & \multicolumn{2}{|c|}{$\begin{array}{c}\text { No. of follicular waves } \\
\text { during an interovulatory interval }\end{array}$} \\
\hline & Two & Three \\
\hline $\begin{array}{l}\text { Interovulatory interval } \\
\text { No. } \\
\text { Length (days) }\end{array}$ & $\begin{array}{c}18 \\
20 \cdot 4 \pm 0 \cdot 3^{a}\end{array}$ & $\begin{array}{c}4 \\
22 \cdot 8 \pm 0 \cdot 6^{b}\end{array}$ \\
\hline $\begin{array}{l}\text { No. of days between emergence of waves* } \\
\text { 1st wave to } 2 \text { nd wave } \\
\text { 2nd wave to } 3 \text { rd wave } \\
\text { 3rd wave to } 4 \text { th wave }\end{array}$ & $\begin{aligned} 9 \cdot 7 & \pm 0 \cdot 2^{\mathrm{e}} \\
10 \cdot 4 \pm 0 \cdot 2^{\mathrm{d}} & \\
\quad & \end{aligned}$ & $\begin{array}{l}9 \cdot 0 \pm 0 \cdot 4^{\mathrm{ef}} \\
7 \cdot 2 \pm 1 \cdot 2^{\mathrm{f}} \\
6 \cdot 7 \pm 0 \cdot 3^{\mathrm{r}}\end{array}$ \\
\hline $\begin{array}{l}\text { First dominant anovulatory follicle } \\
\text { Detection (Day) } \dagger \\
\text { End of growth phase (Day) } \\
\text { Maximum diameter (mm) } \\
\text { Onset of regression (Day) }\end{array}$ & $\begin{aligned}-0 \cdot 2 & \pm 0 \cdot 1 \\
6 \cdot 2 & \pm 0 \cdot 3 \\
17 \cdot 1 & \pm 0 \cdot 5^{\mathrm{h}} \\
13 \cdot 0 & \pm 0 \cdot 4\end{aligned}$ & $\begin{array}{r}-0 \cdot 5 \pm 0 \cdot 3 \\
6 \cdot 5 \pm 0 \cdot 5 \\
16 \cdot 0 \pm 0 \cdot 4^{h} \\
12 \cdot 2 \pm 0 \cdot 5\end{array}$ \\
\hline $\begin{array}{l}\text { Second dominant anovulatory follicle } \\
\text { Detection (Day) } \\
\text { End of growth phase (Day) } \\
\text { Maximum diameter (mm) } \\
\text { Onset of regression (Day) }\end{array}$ & $\begin{array}{l}- \\
-\end{array}$ & $\begin{array}{l}9 \cdot 0 \pm 0 \cdot 0 \\
14 \cdot 2 \pm 0 \cdot 5 \\
12 \cdot 9 \pm 0 \cdot 7^{i} \\
19 \cdot 0 \pm 0 \cdot 0\end{array}$ \\
\hline $\begin{array}{l}\text { Ovulatory follicle } \\
\text { Detection (Day) } \\
\text { Maximum diameter (mm) } \\
\text { Interval from detection to ovulation (days) }\end{array}$ & $\begin{array}{l}9 \cdot 6 \pm 0 \cdot 2^{\mathrm{m}} \\
16 \cdot 5 \pm 0 \cdot 4^{\mathrm{h}} \\
10 \cdot 9 \pm 0 \cdot 4^{\mathrm{p}}\end{array}$ & $\begin{array}{r}16 \cdot 0 \pm 1 \cdot 1^{n} \\
13 \cdot 9 \pm 0 \cdot 4^{i} \\
6 \cdot 8 \pm 0.6^{9}\end{array}$ \\
\hline $\begin{array}{l}\text { Corpus luteum } \\
\text { Onset of regression (Day) } \\
\text { Diameter of ovulatory follicle on day of luteal } \\
\text { regression (mm) } \\
\text { Interval from detection of ovulatory follicle to luteal } \\
\text { regression (days) } \\
\text { Interval from luteal regression to ovulation (days) }\end{array}$ & $\begin{aligned} 16 \cdot 5 & \pm 0 \cdot 4^{s} \\
13 \cdot 5 & \pm 0 \cdot 4^{v} \\
& \\
6 \cdot 9 & \pm 0 \cdot 3^{y} \\
3 \cdot 9 & \pm 0 \cdot 2\end{aligned}$ & $\begin{array}{l}10 \cdot 1 \pm 2 \cdot 3^{w} \\
3 \cdot 2 \pm 1 \cdot 0^{2} \\
3 \cdot 5 \pm 0 \cdot 6\end{array}$ \\
\hline
\end{tabular}

ab,def,hi,mn,pq,st,vw,yz Within each set of superscripts, means with no common superscripts are significantly different.

*For 2-wave and 3-wave intervals, the 3 rd and 4 th waves, respectively, refer to the 1 st wave of the subsequent interovulatory interval.

+Day 0 = day of ovulation. 
Table 2. Temporal relationships between dominant follicles and between dominant and subordinate follicles

\begin{tabular}{|c|c|c|}
\hline Events & No. & $\begin{array}{c}\text { No. of days } \\
\text { between events } \\
\text { (mean } \pm \text { s.e.m. })^{*}\end{array}$ \\
\hline $\begin{array}{l}\text { Two-wave intervals } \\
\text { Emergence of dominant anovulatory follicle and } \\
\text { cessation of growth of subordinate follicle }\end{array}$ & 16 & $2.9 \pm 0.2$ \\
\hline $\begin{array}{l}\text { Emergence of ovulatory follicle and: } \\
\text { (1) Cessation of growth of subordinate follicle } \\
\text { (2) Regression of dominant anovulatory follicle }\end{array}$ & $\begin{array}{l}15 \\
18\end{array}$ & $\begin{array}{l}3 \cdot 0 \pm 0 \cdot 3 \\
3 \cdot 5 \pm 0 \cdot 3\end{array}$ \\
\hline $\begin{array}{l}\text { Three-wave intervals } \\
\text { Emergence of } 1 \text { st dominant anovulatory follicle } \\
\text { and cessation of growth of subordinate follicle }\end{array}$ & 4 & $2 \cdot 8 \pm 0.6$ \\
\hline $\begin{array}{l}\text { Emergence of 2nd dominant anovulatory follicle and: } \\
\text { (1) Cessation of growth of subordinate } \\
\text { (2) Regression of } 1 \text { st dominant follicle }\end{array}$ & $\begin{array}{l}3 \\
4\end{array}$ & $\begin{array}{l}2.7 \pm 0.9 \\
3.2 \pm 0.5\end{array}$ \\
\hline $\begin{array}{l}\text { Emergence of ovulatory follicle and: } \\
\text { (1) Cessation of growth of subordinate follicle } \\
\text { (2) Regression of } 2 \text { nd dominant follicle }\end{array}$ & $\begin{array}{l}3 \\
4\end{array}$ & $\begin{array}{l}2 \cdot 3 \pm 0.3 \\
3 \cdot 0 \pm 1 \cdot 1\end{array}$ \\
\hline
\end{tabular}

* No significant differences among means.

interovulatory-interval lengths of 20 and 23 days were used for the 2-wave and 3-wave intervals, respectively. For the 2-wave intervals, the 2 waves began on mean Days $-0.2 \pm 0 \cdot 1$ and $9.6 \pm 0.2$ and on the normalized interovulatory-interval scale were assigned to Days 0 and 10, respectively. For the 3-wave intervals, the waves began on Days $-0 \cdot 5 \pm 0 \cdot 3,9 \cdot 0 \pm 0 \cdot 0$, and $16 \cdot 0 \pm 1 \cdot 1$ and were normalized to Days 0,9 and 16 , respectively.

The mean days of emergence of the 1st and 2nd waves were not significantly different between 2-wave and 3-wave intervals (Table 1). Within the 2-wave intervals, the number of days between the 1st and 2 nd wave was less $(P<0.05)$ than the number of days between the 2 nd wave and the 1 st wave of the next interovulatory interval. Within the 3 -wave intervals, there were no significant differences in number of days between the emergence of consecutive waves.

Within the 2-wave intervals, the maximum diameter attained by the dominant anovulatory follicle was not different from the diameter of the ovulatory follicle on the day before ovulation (Table 1). Within the 3-wave intervals, the mean maximum diameter of the 1st anovulatory follicle was greater $(P<0.01)$ than for the 2 nd anovulatory follicle and was greater $(P<0.05)$ than for the maximum diameter of the preovulatory follicle. The maximum diameter attained by the preovulatory follicle and the diameter on the day before ovulation were identical for all intervals, except for a small difference $(0.5 \mathrm{~mm})$ for one follicle. In the factorial comparison between the $1 \mathrm{st}$ and 2 nd dominant follicles of the 3-wave intervals, the day effect was significant and the wave effect (1st versus 2 nd waves) approached significance $(P<0.06)$; the interaction of day and wave was not significant.

No significant differences were found between the anovulatory wave of the 2-wave intervals and the 1 st anovulatory wave of the 3-wave intervals. The day effect was significant but the main effect of wave and the day-by-wave interaction were not (Fig. 1). Similarly, the maximum diameter attained, the day of growth cessation, and the day of initiation of follicle regression were not different between the 2 waves (Table 1). The dominant ovulatory follicle differed significantly between the 2-wave and 3-wave intervals in the day of emergence, length of interval from emergence of the follicle to ovulation, and diameter on the day before ovulation (Table 1). Interval from detection of a dominant follicle to cessation of growth of the associated subordinate follicle did not 


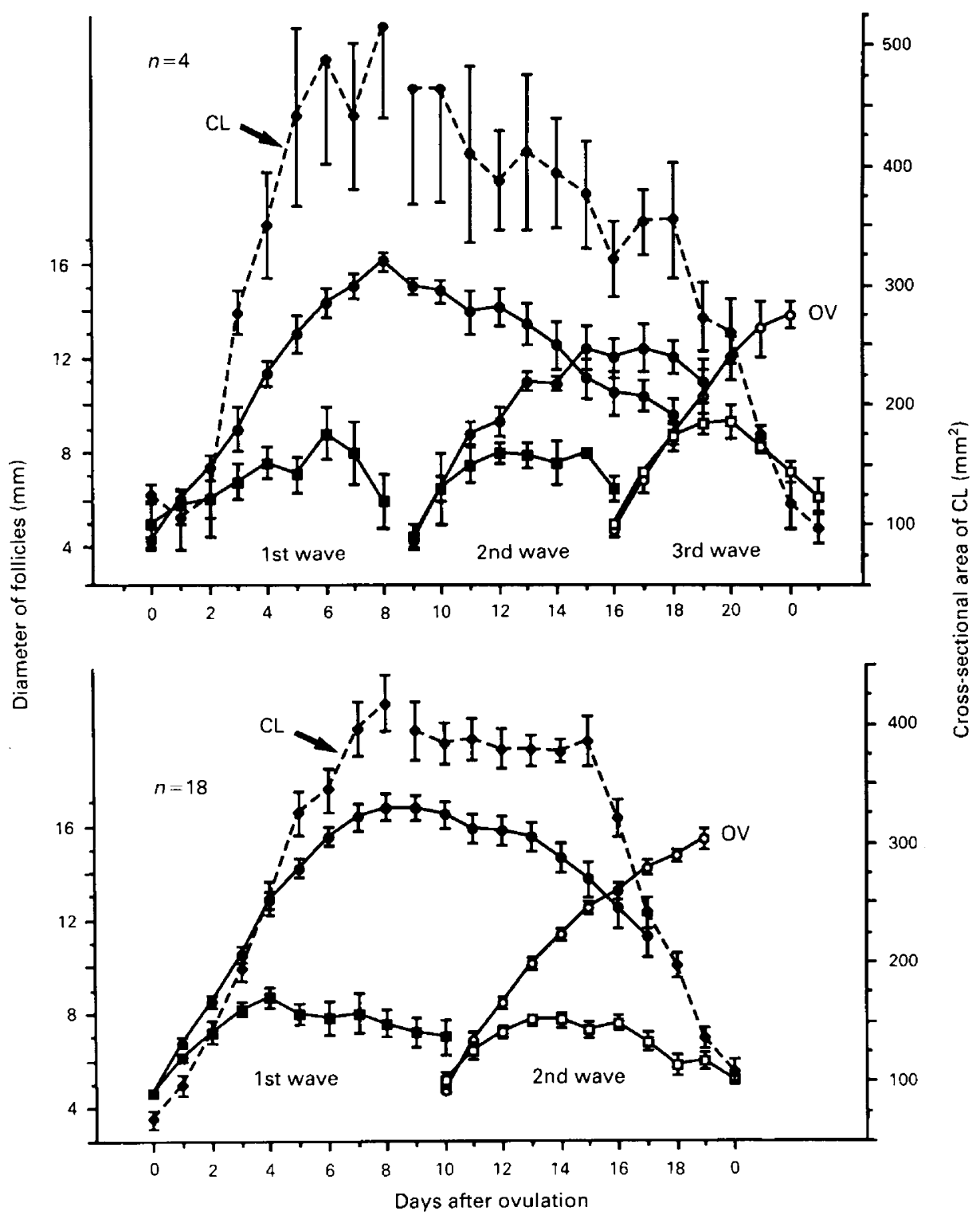

Fig. 1. Mean ( \pm s.e.m.) profiles of diameters of dominant follicles and the largest subordinate and the cross-sectional luteinized area of the corpus luteum (CL) for interovulatory intervals with 3 and 2 follicular waves. Regression $(P<0.05)$ of the corpus luteum began between Days 18 and 20 for 3 -wave intervals and between Days 15 and 16 for 2 -wave intervals. $O V=$ ovulation.

differ among types of waves and did not differ from the interval from detection of a dominant follicle to onset of regression of the previous dominant follicle (Table 2).

The first significant decrease in the cross-sectional luteinized area of the corpus luteum was between Days 15 and 16 for 2-wave intervals and Days 18 and 20 for the 3-wave intervals; the decrease between Days 18 and 19 tended to be significant $(P<0 \cdot 1$; Fig. 1). When the day of regression was defined for individual intervals, the mean day of regression for 2-wave and 3-wave intervals was $16.5 \pm 0.4$ and $19.2 \pm 0.5(P<0.01)$, respectively, but the interval from the defined 
day of luteal regression to ovulation was not significantly different between 2-wave and 3-wave intervals (Table 1). The mean length of the interval from emergence of the ovulatory wave to luteal regression and the mean diameter of the ovulatory follicle on the day of luteal regression were significantly different $(P<0.01$ and $P<0.05$, respectively) between the 2-wave and 3-wave intervals.

\section{Discussion}

The Holstein heifers studied in our laboratory have consistently demonstrated a predominance of 2-wave follicular activity, regardless of whether the studies involved counting and categorizing all ultrasonically detected follicles (Pierson \& Ginther, 1986, 1987) or ultrasonically monitoring individual follicles (Pierson \& Ginther, 1988; Knopf et al., 1989). When results are combined for the previous and present studies utilizing ultrasonic monitoring of individual follicles, 26 of $32(81 \%)$ interovulatory intervals had 2 waves and the remainder had 3. In contrast, two other laboratories reported that only $15 \%$ (4 of 21$)$ of Friesian $\times$ Hereford heifers (Savio et al., 1988) and $20 \%(2$ of 10) Holstein heifers (Sirois \& Fortune, 1988) had 2 follicular waves during an oestrous cycle; most of the remainder had 3 waves. These divergent results indicate that populations of heifers differ in proportion with a given wave pattern; the numbers of observations per study seem too great to attribute the disparity to chance in sampling various heifer populations. The genetic or environmental factors that account for different proportions of 2-wave and 3-wave patterns in various geographic locations are not known. The differences cannot be attributed to breed or parity since Holstein heifers were used in studies with opposite results. Technical error also is not a reasonable explanation considering the magnitude of the differences. In the present study, the 18 two-wave intervals were from 11 heifers and the 4 three-wave intervals were from 3 heifers, but the study was not designed to determine whether wave pattern tends to be repeatable within heifers. Two of the previous studies with opposite results utilized only one oestrous cycle (Sirois \& Fortune, 1988) or interovulatory interval (Knopf et al., 1989) per heifer, and therefore the differences cannot be attributed to repeated use of animals with a propensity for a given wave pattern.

Although the underlying factors that influence the proportion of 2-wave and 3-wave patterns among heifer populations is not known, there are two distinct series of ovarian events that could determine whether a 3rd wave emerges during a given interovulatory interval. First, a shorter interval between the emergence of sequential waves could allow more waves to appear even when the length of the interovulatory interval is held constant. Second, a longer interovulatory interval could allow an additional wave to emerge even when the interval between waves is constant.

In the present study, the dominant follicle of the anovulatory wave of 2-wave intervals did not differ from the dominant follicle of the first wave of 3-wave intervals for any of the characteristics studied. Similarly, Savio et al. (1988) did not find significant differences between these follicles for any of 5 characteristics. The day of first detection of the ovulatory follicle of 2-wave intervals (mean, Day 9.6) did not differ significantly from the day of detection of the 2nd dominant anovulatory follicle of the 3-wave intervals (Day 9.0). In addition, the development and size of the corpus luteum during the first half of the interovulatory intervals did not differ between 2-wave and 3-wave intervals. In summary, no differences were found during the first half of the interovulatory interval that were associated with the emergence of a 3 rd wave of follicular activity during some intervals.

Within the 3-wave intervals, the day-to-day mean diameter profile of the dominant follicle of the 2nd wave was not as pronounced as that of the dominant follicle of the first wave; the mean maximum diameter was $3 \mathrm{~mm}$ smaller, in agreement with the study of Sirois \& Fortune (1988), who found that the second anovulatory follicle was an average of $2 \mathrm{~mm}$ smaller than the first.

The mean length of the interovulatory interval was an average of 2.4 days longer and the luteal phase was 2.7 days longer in 3-wave than in 2-wave intervals, whereas the length of interval from luteal regression to ovulation was not different. The increased length of 3 -wave intervals, therefore, 
was attributable entirely to a longer luteal phase. In previous studies (Savio et al., 1988; Sirois \& Fortune, 1988), the mean length of oestrous cycles was not significantly different between 2-wave and 3-wave patterns, but the difference between wave patterns was in the same direction as in the present study.

The ovulatory follicle of 3-wave intervals differed from that of 2-wave intervals as follows: (1) later emergence (Day 16 versus Day 10), (2) shorter interval from emergence to ovulation (7 days versus 11 days) and (3) smaller preovulatory diameter (14 mm versus $16 \mathrm{~mm}$ ). Thus, the 6-day difference in time of emergence was partly compensated for by an interval to ovulation that was 4 days shorter, resulting in only a 2-day increase in length of the interovulatory interval.

Luteal regression occurred an average of 7 days and 3 days after emergence of the ovulatory follicle in 2-wave and 3-wave intervals, respectively. The shorter interval from emergence of the ovulatory follicle to luteolysis in the 3-wave intervals accounts for the smaller follicle at the time of luteolysis. For all interovulatory intervals, 2-wave and 3-wave, luteal regression occurred after emergence of the ovulatory follicle and, with one exception, before the emergence of another follicular wave. In the exception, an anovulatory wave emerged the day before the onset of luteolysis, but the dominant follicle of the previous wave continued to develop and ovulated. The dominant follicle that emerged just before luteolysis reached a diameter of $11 \mathrm{~mm}$ and then began regressing at the end of the interovulatory interval.

These results did not permit attributing the emergence of a 3 rd wave to a shorter interval between waves; the anovulatory wave of 3-wave patterns did not begin earlier than that of 2-wave patterns. In this regard, however, only 4 interovulatory intervals with 3 waves were available, and further studies with larger numbers may show that earlier emergence of waves increases the probability for a $3 \mathrm{rd}$ wave. In this regard, Sirois \& Fortune (1988) reported intervals of 9 days between waves in 2-wave oestrous cycles $(n=2)$ and approximately 7 days between waves in 3wave cycles $(n=7)$. Despite the small number of 3 -wave intervals in the present study, significant differences were found which permitted attribution of the emergence of a 3rd wave to a longer luteal phase.

For all dominant anovulatory follicles, the static phase did not give way to the regressive phase until after emergence of the next dominant anovulatory or ovulatory follicle. The mean interval from follicle emergence to onset of regression of the preceding follicle ( $\sim 3$ days) was comparable to the mean interval from emergence of a dominant follicle to cessation of growth of its largest subordinate. These temporal associations are compatible with the hypothesis that the dominant follicle exerts a profound inhibitory effect on its subordiate follicles and on the static dominant follicle of the preceding wave. The dominant anovulatory follicle during its growth phase may also have suppressed development of the next wave to the detectable stage $(4-5 \mathrm{~mm})$; in all instances, the dominant follicle was in the static phase when the next wave was first detected. The apparent wavesuppression phenomenon was also associated with the dominant ovulatory follicle until just before ovulation; this may account for the prolonged interval between emergence of the ovulatory wave of 2-wave patterns and the emergence of the first wave of the next interovulatory interval. Although it cannot be stated unequivocally that production of an inhibitory factor by the dominant follicles played a key role in the interfollicular associations in the present study, the temporal relationships encourage investigation of this possibility. In this regard, bovine follicular fluid is known to contain a non-steroidal factor that has follicle-inhibiting activity in heifers (Miller et al., 1979).

Although determination of the concentrations of various hormones was not incorporated into this study, the morphological and temporal results provide a rationale for hypothesis building and testing. An overall interpretation that seems compatible with the results in this group of heifers is as follows. Waves of follicular activity occurred periodically. A dominant follicle emerged from each wave and during its growing phase caused regression of the subordinate follicles of the wave and the static dominant follicle of the previous wave. During its growing phase and first portion of its static phase, the dominant follicle also suppressed the emergence of another wave. The periodic development of waves continued until the corpus luteum regressed, and therefore a 3rd wave of 
follicular activity was more likely to occur when the life-span of the corpus luteum was prolonged. The viable dominant follicle that was present at the time luteolysis became the preovulatory follicle. The post-luteal phase of the oestrous cycle involved continued growth of the ovulatory follicle with suppression by the ovulating follicle of the emergence of additional waves until the approach of ovulation.

Supported by College of Agricultural and Life Sciences, University of Wisconsin-Madison and USDA Grant 87-CRSR-2-3158. We thank Lisa Kulick for graphic and computer assistance; Sophie Yap for statistical assistance; and Sharon Schade for manuscript preparation. L.K. is Research Fellow of the Deutsche Forschungsgemeinschaft and the H. W. Schauman Stiftung and is on leave from Department of Physiology, Technical University Munich, Weihenstepan, Federal Republic of Germany. J.K. is supported by a fellowship from the Medical Research Council of Canada.

\section{References}

Ireland, J.J. \& Roche, J.F. (1987) Hypotheses regarding development of dominant follicles during a bovine estrous cycle. In Follicular Growth and Ovulation Rate in Farm Animals, pp. 1-18. Eds J. F. Roche \& D. O'Callaghan. Martinus Nijhoff, Dordrecht.

Knopf, L., Kastelic, J.P., Schallenberger, E. \& Ginther, O.J. (1989) Ovarian follicular dynamics in heifers. Test of two-wave hypothesis by ultrasonically monitoring individual follicles. Dom. Anim. Endocr. 6, III-119.

Miller, K.F., Critser, J.K., Rowe, R.F. \& Ginther, O.J. (1979) Ovarian effects of bovine follicular fluid treatment in shesp and cattle. Biol. Reprod. 21, 537-544.

Pierson, R.A. \& Ginther, O.J. (1986) Ovarian follicular populations during early pregnancy in heifers. Theriogenology 26, 649-659.

Pierson, R.A. \& Ginther, O.J. (1987) Follicular populations during the estrous cycle in heifers: I. Influence of day. Anim. Reprod. Sci. 14, 165-176.
Pierson, R.A. \& Ginther, O.J. (1988) Ultrasonic imaging of the ovaries and uterus in cattle. Theriogenology 29 , 21-37.

Rajakoski, E. (1960) The ovarian follicular system in sexually mature heifers with special reference to seasonal, cyclical, and left-right variations. Acta endocr., Copenh., Suppl. 52, 7-68

SAS (1985) User's Guide: Statistics, Version 5 edn. SAS Institute Inc., Cary.

Savio, J.D., Keenan, L., Boland, M.P. \& Roche, J.F. (1988) Pattern of growth of dominant follicles during the oestrous cycle in heifers. J. Reprod. Fert. 83, $663-671$.

Sirois, J. \& Fortune, J.E. (1988) Ovarian follicular dynamics during the estrous cycle in heifers monitored by real-time ultrasonography. Biol. Reprod. 39, 308317.

Received 5 January 1989 